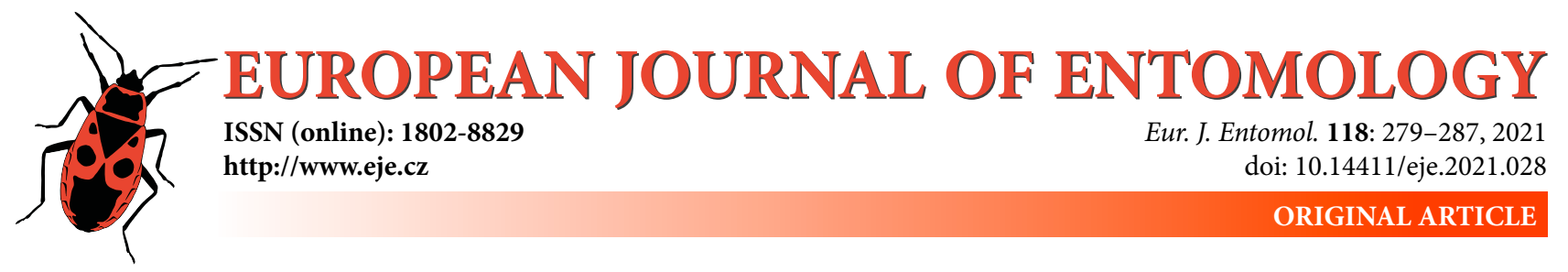

\title{
Effect of the instar of the pear psyllid Cacopsylla pyri (Hemiptera: Psyllidae) on the behaviour and fitness of the parasitoid Trechnites insidiosus (Hymenoptera: Encyrtidae)
}

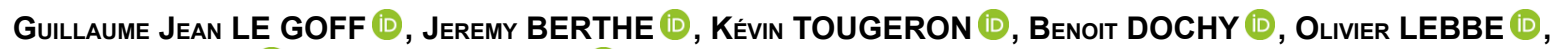 \\ FRANÇOIS RENOZ iD and THIERRY HANCE $\mathbb{D}$
}

Earth and Life Institute, Ecology and Biodiversity, UC Louvain, Croix du sud 4-5 bte L7.07.04, 1348 Louvain-la-Neuve, Belgium; e-mails: guillaume.legoff@uclouvain.be, berthe.jeremy@outlook.be, kevin.tougeron@uclouvain.be, benoit.dochy@uclouvain.be, olivier.lebbe@uclouvain.be, francois.renoz@uclouvain.be, thierry.hance@uclouvain.be

Key words. Psyllidae, Cacopsylla pyri, Encyrtidae, Trechnites insidiosus, parasitoid, behaviour, host instar, locomotor activity, host acceptance, host suitability, offspring quality, pear orchards, biological control

\begin{abstract}
Improved methods of integrated pest management of the pear psyllid Cacopsylla pyri (L.), the primary pest of pear in Europe and North America, are needed. Trechnites insidiosus (Crawford) is the most abundant parasitoid of $C$. pyri in pear orchards, where it is present early in the psyllid infestation period. However, little is known about its general biology, interaction with its host and potential as a control agent. The objective of this laboratory study was to evaluate the behaviour of a specialist parasitoid when presented with different larval instars of $C$. pyri, and assess the quality of the next generation of parasitoids. $T$. insidiosus was able to insert its ovipositor into all host instars. However, the fourth instar of the host appeared to be the most suitable in terms of behavioural acceptance, time spent walking, antennal activity and progeny development (mummy formation, development time and tibial length). In addition, we report a low frequency of host-feeding behaviour by this parasitoid. From a biological control perspective, we suggest that favouring $T$. insidiosus, either through mass releases or conservation of naturally present populations, when the first generation of psyllids reach the fourth instar, would maximize the chance of controlling psyllid populations in pear orchards.
\end{abstract}

\section{INTRODUCTION}

Pear (Pyrus communis L.) is one of the major fruit crops in temperate climates, it is ranked second in terms of fruit production in Europe with more than 100000 hectares dedicated to its cultivation and approximately 2 million tons of pears produced in orchards in 2019 (Tougeron et al., 2021; FAOSTAT, 2021). Pear psyllids are important pests of commercial pear, most notably Cacopsylla pyri (L.) in Europe and C. pyricola (Foerster) in North America and Europe (Horton, 1999). Honeydew excretions produced by C. pyri immatures are colonized by sooty moulds, which results in marked fruit and reductions in marketable fruit (Civolani, 2012; Sanchez \& Ortin-Angulo, 2012). These pests also transmit various phytopathogens such as the phytoplasma Candidatus Phytoplasma pyri (Seemüller \& Schneider, 2004), which is responsible for pear decline disease (Civolani, 2012).

Control of pear psyllids is currently mainly based on Integrated Pest Management (IPM) (DuPont et al., 2021), which relies on the use of multiple, complementary tactics in an environmentally and economically sound manner. However, resistance to insecticides has resulted in this psyllid being a pest in many orchards (Buès et al., 2003; Erler, 2004; Civolani et al., 2007). With the banning of an increasing number of phytochemicals (Lamichhane et al., 2019), it is important to develop new approaches for the control of pear psyllids. Incorporating biological control into an IPM programs can increase pear psyllids control. For example, spiders, ants or anthocorid bugs may help in the management of pear psyllid populations (Sanchez \& Ortin-Angulo, 2012; Sanchez et al., 2020; Gajski \& Pekár, 2021) and mass releases of anthocorids into orchards can effectively reduce pear psyllid populations (Sigsgaard et al., 2006a, b). However, their abundance in pear orchards is not always sufficient to regulate psyllid populations below sustainable levels (Booth, 1992; Erler, 2004; Civolani, 2012). That is why it is crucial to study other natural enemies of the pear psyllid and develop new biological control solutions for use by pear growers.

The use of specialist parasitoids are promising alternatives or for complementing the use of generalist predators, due to their host-specificity, foraging capacity, high fecundity rate and lack of negative side-effects on the environment. The parasite fauna of $C$. pyri is quite diverse and 
several species are reported in pear orchards: Trechnites insidiosus (Crawford), Prionomitus mitratus (Dalman), $P$. tiliaris (Dalman), Endopsylla sp., Psyllaephagus procerus Marcet, Syrphophagus ariantes (Walker), Syrphophagus taeniatus (Förster) and Tamarixia sp. (Armand et al., 1990, 1991; Erler, 2004; Guerrieri \& Noyes, 2009; JerinicProdanovic et al., 2010). However, there have been no attempts to rear these species for mass production, and little information is available on their biology and general ecology (Tougeron et al., 2021). Of these parasitoids, $T$. insidiosus is consistently cited as the most abundant species in pear orchards (Herard, 1985; Armand et al., 1990, 1991; Avilla \& Artigues, 1992; Booth, 1992; Erler, 2004; Miliczky \& Horton, 2005; Bufaur et al., 2010; Sanchez \& Ortin-Angulo, 2012), even though it is adversely affected by chemical treatments (Burts, 1983; Lacey et al., 2005; Sanchez \& Ortin-Angulo, 2012) and relatively high levels of hyperparasitism (McMullen, 1966; Armand et al., 1990, 1991; Sanchez \& Ortin-Angulo, 2012).

Trechnites insidiosus is endemic to Eurasia and extended its distribution to North America during the 19th and 20th centuries (Tougeron et al., 2021) (for a detailed description of its geographical distribution, see Guerrieri \& Noyes, 2009). In 1965, T. insidiosus was intentionally introduced into California as a biological control agent to limit populations of introduced psyllid pests (Bartlett \& Clausen, 1978), but no information is available on its establishment there and effectiveness in controlling psyllids. It is a koinobiont parasitoid that has interesting attributes for IPM of pear psyllids. First, it is active from early April to late November (Herard, 1985; Armand et al., 1990, 1991; Bufaur et al., 2010; Oudeh et al., 2013; DuPont \& Strohm, 2020), which means it can be active at fairly low temperatures. The first generation of Trechnites insidiosus is not hyper parasitized (Armand et al., 1990, 1991). This parasitoid is active when the first generation of pear psyllids are present, but before the arrival of predators that would complement its action. Several field studies have revealed peak parasitism levels of natural populations that vary between 30 to $100 \%$ depending on location (Jaworska et al., 1998; Erler, 2004; Bufaur et al., 2010; Oudeh et al., 2013), suggesting the effective control of psyllid populations by $T$. insidiosus (Talitski, 1996 in Unruh et al., 1994). However, to date, there are few laboratory studies on the behaviour of $T$. insidiosus when parasitizing the pear psyllid Cacopsilla pyri.

In this study, the interactions between the pear psyllid $C$. pyri and the parasitoid T. insidiosus are recorded and the most suitable host instars for its development determined. The five immature instars of the pear psyllid differ in terms of their physiology, behaviour and overall quality and suitability for this parasitoid (Tougeron et al., 2021). Females of hymenopteran parasitoids are able to assess the quality of potential hosts they encounter, optimize their choice and maximize their offspring's fitness (Godfray, 1994; Mackauer et al., 1996). We recorded the behaviour of female $T$. insidiosus parasitizing $C$. pyri as well as proxies of the fitness of their offspring that developed in the different instars of the host. The quality of the next generation of parasitoids was assessed in terms of their developmental time, fecundity, size and sex ratio, which are commonly used as proxies for assessing parasitoid fitness (Colinet et al., 2005).

Previous studies report that females of $T$. insidiosus prefer to lay eggs in the fourth and fifth immature instars of the pear psyllid, C. pyri (Armand et al., 1990, 1991), while for $C$. pyricola, it is reported that this parasitoid oviposit in all five instars (Gutierrez, 1966; McMullen, 1966; Booth 1992), but prefers the third and fourth instars (Gutierrez, 1966). Given the differences in the results concerning the oviposition preferences of $T$. insidiosus, it is likely that females oviposit in all the larval instars of $C$. pyri, but prefer the more mature instars which are more suitable hosts from a nutritional standpoint. We also hypothesized that potential fitness of parasitoids emerging from hosts instars that were parasitized late in their development is greater than that of individuals emerging from hosts that were parasitized early in their development.

\section{MATERIAL AND METHODS}

\section{Insects and rearing conditions}

The insects used in the experiments were initially collected from populations C. pyri sampled in 2013 and of T. insidiosus in 2016 in the experimental pear orchard of Proefcentrum voor Fruitteelt, Sint-Truiden, Belgium $\left(50.81^{\circ} \mathrm{N}, 5.21^{\circ} \mathrm{E}\right)$. Populations were maintained in the laboratory on pear trees in such a way that the instar and age of the insects was known (Berthe, 2018), under the following conditions: $24^{\circ} \mathrm{C}, 60 \%$ relative humidity and a $18 \mathrm{~L}$ : 8D photoperiod.

\section{The influence of host instar on parasitoid behaviour}

Groups of twenty immature psyllid of the same instar (first-, second-, third-, fourth- and fifth-instar) were placed in artificial diet feeders for two hours before a female parasitoid was introduced, so that the immature psyllids had produced honeydew, which stimulates oviposition behaviour in this parasitoid (Gutierrez, 1966; McMullen, 1966). Artificial feeder consisted of $500 \mu \mathrm{L}$ of a nutritive solution (supplied by Viridaxis SA, Belgium) put on top of a $5.5 \mathrm{~cm}$ diameter Petri dish, and spread using a $25 \mathrm{~cm}^{2}$ piece of parafilm stretched over the dish, in a way that the fluid is under the thin parafilm membrane through which the insect can insert its stylets and feed. By using an artificial diet any influence of the host plant on the behaviour of the parasitoids is avoided.

The different immature instars were identified based on morphological criteria: the first three instars are creamy-yellow coloured, while the fourth and fifth instars vary between greenishbrown to dark-brown (Chang, 1977). The first instar is the same size as psyllid eggs, the second instar is twice as large and third instar has wing pads, which gradually grow and become clearly visible in the following fourth and fifth instars (Chang, 1977). A mated T. insidiosus female that was less than $48 \mathrm{~h}$ old was placed during the afternoon in the centre of the set up and its behaviour recorded for thirty minutes using a Sony handycam (HDR XR200VE). There were ten replicates of the interactions between each host instar and a naïve parasitoid female. Using the event recorder software ODRec 3.0 (C) Samuel Péan) the following were quantified: (1) the number of antennal contacts with the psyllid, (2) number of ovipositor insertions into the host (Albittar et al., 2016; Augustin et al., 2020), (3) time spent walking (expressed as a percentage of the total time), (4) time spent resting (expressed as a percentage of the total time), (5) number of host-feeding 
events [Host feeding is the consumption of host fluid exuding from oviposition wounds by an adult female parasitoid (Heimpel \& Collier, 1996)], (6) time spent feeding on the host (expressed as a percentage of the total time), (7) time spent grooming (expressed as a percentage of the total time). The host acceptance rate was the number of ovipositor insertions divided by the number of antennal contacts.

\section{The influence of host instar on parasitism and offspring quality}

After the behavioural bioassays, all psyllid immatures from the ten replicates of each treatment were placed on the same pear tree for 14 days to await the formation of mummies (i.e., dead psyllids containing a developing parasitoid). We used in-vitrocultivated pear trees (Williams cultivar) that were between one and two years old, and between 0.75 and $1 \mathrm{~m}$ high. Plants were obtained from Battistini Vivai (www.battisti-rebschule.it) and kept in individual cages in a climatic chamber at $24^{\circ} \mathrm{C}$. After 14 days, pear trees were checked daily for the presence of mummies and adult psyllids. Each mummy was then isolated in a falcon tube with a drop of honeydew until the parasitoid emerged. Development time was measured as the number of days from oviposition to adult emergence. Host suitability was measured in terms of the number of mummies divided by the number of ovipositor insertions. The proportion mummies that gave rise to adults was the number of adult parasitoid that emerged divided by the total number of mummies, in each treatment. Finally, the sex-ratio was the number of males divided by the total number of adults emerging. Three days after emergence, parasitoids (males and females) were stored in a freezer at $-20^{\circ} \mathrm{C}$ for future measurements of tibial size and egg load.

The length of the tibia was used as a proxy for individual body size. The left hind tibia of each individual was measured using the software ImageJ 1.440 (Rasband, W.S., US National Institutes of Health, Bethesda, MD, USA). To estimate their egg load, the abdomen of each female was squeezed beneath a cover slip on a microscope slide (Mansfield \& Mills, 2002): the female was placed on an object blade with a small amount of water and crushed with a coverslip. To better extract the eggs, the pressure exerted on the coverslip started at the head end and moved towards the abdomen. Only ellipsoidal mature eggs (Fig. 1) were counted.

\section{Statistical analysis}

Generalized linear models (GLMs) were fitted to the data to test the potential influence of host instar (explanatory variable, with five levels) on female parasitoid behaviour and emerging

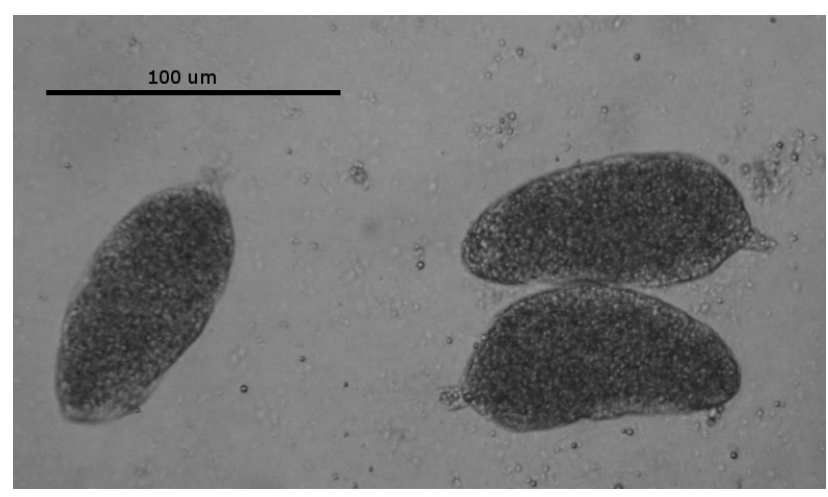

Fig. 1. Mature eggs of Trechnites insidiosus.

parasitoid quality. Response variables were the number of host feeding events (Poisson distribution), time spent host feeding (Gaussian distribution), time spent grooming (Gaussian distribution), time spent walking (Gaussian distribution), time spent resting (Gaussian distribution), number of antennal contacts (Poisson distribution), number of ovipositor insertions (Poisson distribution), host acceptance (Gaussian distribution), number of mummies (Poisson distribution), host suitability (Gaussian distribution), proportion of mummies that produced adult parasitoids (Binomial distribution) and egg load (Poisson distribution).

We also used a GLM (Gaussian distribution) to test the potential influence of sex, host instar and of their interaction, on the tibial size and the developmental time of emerging parasitoids. GLMs were followed by Tukey post hoc tests to compare each level of the same factor (host instar and sex). Results of Tukey post hoc tests are shown in supplementary files (S1). In addition, Spearman correlation tests were performed between tibial size and egg load at emergence for each female and each host instar. Finally, using $\chi^{2}$ tests, we compared the sex ratio of parasitoids emerging from each instar to a $50 / 50$ theoretical sex ratio.

Statistical analyses were performed using $\mathrm{R}$ version 4.1.0 $\mathrm{R}$ Core Team 2016 for Statistical Computing for Mac. All tests were applied using two-tailed hypotheses and significance level set at 0.05 .

\section{RESULTS}

\section{Influence of host instar on parasitoid behaviour}

The number of antennal contacts varied significantly with the host instar $\left(\chi^{2}=800.30, \mathrm{DF}=4, \mathrm{P}<0.001\right)$. The

Table 1. Mean numbers and mean durations \pm standard deviations of the different types of behaviour recorded and number of replicates, in brackets, for each psyllid instar. Different letters indicate significant differences using Tukey HSD tests.

\begin{tabular}{|c|c|c|c|c|c|}
\hline & Instar 1 & Instar 2 & Instar 3 & Instar 4 & Instar 5 \\
\hline Number of antennal contacts & $\begin{array}{c}17.50 \pm 21.06 a \\
(n=10)\end{array}$ & $\begin{array}{c}9.60 \pm 13.66 b \\
(n=10)\end{array}$ & $\begin{array}{c}32.10 \pm 30.19 c \\
(n=10)\end{array}$ & $\begin{array}{c}31.70 \pm 16.26 c \\
(n=10)\end{array}$ & $\begin{array}{c}16.00 \pm 10.19 a \\
(n=10)\end{array}$ \\
\hline Number of ovipositor insertions & $\begin{array}{c}10.00 \pm 13.33 a \\
(n=10)\end{array}$ & $\begin{array}{c}4.70 \pm 7.90 b \\
(n=10)\end{array}$ & $\begin{array}{c}14.80 \pm 11.72 c \\
(n=10)\end{array}$ & $\begin{array}{c}17.80 \pm 11.31 c \\
(n=10)\end{array}$ & $\begin{array}{c}4.00 \pm 3.62 b \\
(n=10)\end{array}$ \\
\hline Host acceptance & $\begin{array}{c}0.56 \pm 0.27 a \\
\quad(n=6)\end{array}$ & $\begin{array}{c}0.54 \pm 0.31 a \\
\quad(n=5)\end{array}$ & $\begin{array}{c}0.50 \pm 0.17 a \\
(n=9)\end{array}$ & $\begin{array}{c}0.55 \pm 0.15 a \\
(n=10)\end{array}$ & $\begin{array}{c}0.22 \pm 0.11 b \\
(n=10)\end{array}$ \\
\hline$\%$ of time spent walking & $\begin{array}{c}28.27 \pm 21.72 a b \\
(n=10)\end{array}$ & $\begin{array}{c}18.49 \pm 16.34 a \\
(n=10)\end{array}$ & $\begin{array}{c}36.06 \pm 18.77 a b \\
(n=10)\end{array}$ & $\begin{array}{c}33.32 \pm 6.91 a b \\
(n=10)\end{array}$ & $\begin{array}{c}42.26 \pm 10.73 b \\
(n=10)\end{array}$ \\
\hline$\%$ of time spent resting & $\begin{array}{c}16.73 \pm 25.22 a b \\
(n=10)\end{array}$ & $\begin{array}{c}32.14 \pm 31.67 a \\
(n=10)\end{array}$ & $\begin{array}{c}3.76 \pm 6.14 b \\
(n=10)\end{array}$ & $\begin{array}{c}0.86 \pm 1.53 b \\
(n=10)\end{array}$ & $\begin{array}{c}0.71 \pm 1.84 b \\
\quad(n=10)\end{array}$ \\
\hline Number of host feeding events & $\begin{array}{c}0.00 \pm 0.00 a \\
(n=10)\end{array}$ & $\begin{array}{c}0.10 \pm 0.32 a \\
(n=10)\end{array}$ & $\begin{array}{c}0.10 \pm 0.32 a \\
(n=10)\end{array}$ & $\begin{array}{c}0.10 \pm 0.32 a \\
\quad(n=10)\end{array}$ & $\begin{array}{c}0.00 \pm 0.00 a \\
(n=10)\end{array}$ \\
\hline$\%$ of time spent host feeding & $\begin{array}{c}0.00 \pm 0.00 a \\
(n=10)\end{array}$ & $\begin{array}{c}0.20 \pm 0.62 a \\
(n=10)\end{array}$ & $\begin{array}{c}0.01 \pm 0.04 a \\
(n=10)\end{array}$ & $\begin{array}{c}0.22 \pm 0.70 a \\
(n=10)\end{array}$ & $\begin{array}{c}0.00 \pm 0.00 a \\
(n=10)\end{array}$ \\
\hline$\%$ of time spent grooming & $\begin{array}{c}36.16 \pm 19.97 \mathrm{a} \\
(n=10)\end{array}$ & $\begin{array}{c}40.19 \pm 16.67 a \\
(n=10)\end{array}$ & $\begin{array}{c}40.15 \pm 21.65 a \\
(n=10)\end{array}$ & $\begin{array}{c}41.81 \pm 11.04 a \\
(n=10)\end{array}$ & $\begin{array}{c}49.74 \pm 11.01 a \\
(n=10)\end{array}$ \\
\hline
\end{tabular}


minimum value was recorded for females of $T$. insidiosus presented with second instar psyllids and the maximum for those presented with third and fourth instar psyllids (Table $1)$. The average number of ovipositor insertions in the different psyllid instars differed significantly $\left(\chi^{2}=443.92\right.$, DF $=4, \mathrm{P}<0.01)$ : there were significantly fewer ovipositor insertions recorded for second instar psyllids than third, fourth and fifth instars (Table 1). Acceptance of the different instars of psyllids as hosts by parasitoids differed significantly $(\mathrm{F}=5.01 ; \mathrm{DF} 1=4, \mathrm{DF} 2=35, \mathrm{P}<0.01)$, with the acceptance of fifth instars lower than that of all other instars (Table 1).

Host instar significantly influenced the time parasitoids spent walking $(\mathrm{F}=3.19, \mathrm{DF} 1=4, \mathrm{DF} 2=45, \mathrm{P}<0.05)$. In the presence of fifth instars, parasitoid spent significantly more time walking, than in the presence of second instars (Table 1). Host instar had a significant effect on the time spent resting $(\mathrm{F}=5.50, \mathrm{DF} 1=4, \mathrm{DF} 2=45, \mathrm{P}<0.01)$. Parasitoids presented with third, fourth and fifth instars spent less time resting than when presented with second instars (Table 1).

The average number parasitoids recorded feeding on psyllids was very low; for each psyllid instar about 1 out of 200 were killed and then eaten by a parasitoid with the percentage of the total time spent feeding being only $0.10 \%$. There were no significant differences in the frequency $\left(\chi^{2}\right.$ $=0.19, \mathrm{DF}=4, \mathrm{P}=0.10)$ or the duration of host-feeding $(\mathrm{F}=0.72, \mathrm{DF} 1=4, \mathrm{DF} 2=45, \mathrm{P}=0.58)$ for the different instars (Table 1). Independent of the instar presented the parasitoid spent a lot, but similar percentage of the total time $(42 \%)$ grooming $(\mathrm{F}=0.90, \mathrm{DF} 1=4, \mathrm{DF} 2=45, \mathrm{P}=$ 0.47) (Table 1).

\section{Influence of host instar on parasitism and offspring quality}

The average number of mummies produced differed significantly in the different treatments $\left(\chi^{2}=111.22\right.$, DF $=4, \mathrm{P}<0.001)$, with a higher mean number of mummies produced when the parasitoids parasitized third and fourth instar psyllids than first and second instar psyllids (Table 2). Host suitability was significantly dependent on psyllid instar $(\mathrm{F}=8.50, \mathrm{DF} 1=4, \mathrm{DF} 2=34, \mathrm{P}<0.001)$, with first instar hosts less suitable than third instar hosts. Fifth instar psyllid were unsuitable as no mummies developed in this treatment (Table 2). The proportion of mummies producing adults did not vary significantly between treatments $\left(\chi^{2}\right.$ $=44.463, \mathrm{DF}=3, \mathrm{P}>0.05)$. Of the 162 mummies produced, 155 gave rise to adults. All mummies of third instar psyllids (72/72) produced adults, whereas two of the first and fourth instar mummies failed to produce adults $(2 / 14$ and $2 / 60$, respectively) and three of the second instar mummies failed to produce adults $(3 / 16)$.

Parasitoids emerging from hosts that were parasitized in the first, second and third instar had a balanced sex ratio $\left(\chi^{2}\right.$ $=0.5, \mathrm{P}>0.5, \chi^{2}=0.8, \mathrm{P}>0.4, \chi^{2}=1.48, \mathrm{P}>0.2$, respectively), whereas those emerging from hosts that were parasitized in the fourth instar had a sex ratio that was skewed in favour of females ( 37 females for 8 males) $\left(\chi^{2}=8.52, \mathrm{P}\right.$ $<0.01$ ) (Table 2). Tibial lengths of parasitoids differed significantly between the sexes, males being smaller than females $(0.33 \pm 0.03 \mathrm{~mm}$ vs. $0.35 \pm 0.02 \mathrm{~mm}$, respectively), regardless of host instar $(\mathrm{F}=43.35, \mathrm{DF} 1=1, \mathrm{DF} 2=152, \mathrm{P}$ $<0.001$ ) (Table 2). Tibial length also varied with host instar $(\mathrm{F}=3.33, \mathrm{DF} 1=3, \mathrm{DF} 2=149, \mathrm{P}<0.05)$. Male and female parasitoids emerging from second instars were on average smaller than those from other instars (Table 2). No interaction was detected between sex and instar $(\mathrm{F}=0.96, \mathrm{DF} 1=$ $3, \mathrm{DF} 2=146, \mathrm{P}=0.41)$.

There was no effect of host instar on female egg load, which was an average of $10.94 \pm 9.00$ mature eggs in all experiments $\left(\chi^{2}=549.71, \mathrm{DF}=3, \mathrm{P}>0.2\right)$ (Table 2$)$. However, a significant correlation between tibial length and female egg load was recorded for females that developed in fourth instar hosts (Spearman's $\mathrm{R}=0.50, \mathrm{P}<0.001, \mathrm{n}=$ 46), but not for females that emerged from other instars $(\mathrm{R}$ $=0.38, \mathrm{P}>0.05, \mathrm{n}=9, \mathrm{R}=0.66, \mathrm{P}>0.05, \mathrm{n}=9$, and $\mathrm{R}=$ $0.12, \mathrm{P}>0.05, \mathrm{n}=35$, for instar 1,2 and 3 , respectively) (Fig. 2). The developmental time of parasitoids in the different host instars differed significantly $(\mathrm{F}=36.11$, $\mathrm{DF} 1=$ $3, \mathrm{DF} 2=149, \mathrm{P}<0.001)$. Adult parasitoids that developed in first instar hosts took longer to emerge from the mummies than those that developed in other host instars (Table 2). There was no significant difference in development

Table 2. Mean \pm standard deviation of the different parameters recorded for the parasitoids that emerged from each of the psyllid instars. Different letters indicate significant differences according to Tukey HSD tests.

\begin{tabular}{|c|c|c|c|c|c|}
\hline & Instar 1 & Instar 2 & Instar 3 & Instar 4 & Instar 5 \\
\hline Number of mummies & $\begin{array}{c}1.33 \pm 1.73 a \\
(n=10)\end{array}$ & $\begin{array}{c}1.44 \pm 2.65 a \\
(n=10)\end{array}$ & $\begin{array}{l}6.55 \pm 4.61 b \\
\quad(n=10)\end{array}$ & $\begin{array}{l}5.78 \pm 3.67 b \\
\quad(n=10)\end{array}$ & $\begin{array}{c}0.00 \pm 0.00 c \\
(n=10)\end{array}$ \\
\hline Host suitability & $\begin{array}{c}0.15 \pm 0.18 \text { ac } \\
\quad(n=6)\end{array}$ & $\begin{array}{l}0.52 \pm 0.28 a b \\
\quad(n=5)\end{array}$ & $\begin{array}{l}0.60 \pm 0.36 b \\
\quad(n=10)\end{array}$ & $\begin{array}{c}0.40 \pm 0.24 a b \\
(n=10)\end{array}$ & $\begin{array}{c}0.00 \pm 0.00 \mathrm{c} \\
(\mathrm{n}=9)\end{array}$ \\
\hline Sex ratio & 0.33 & 0.30 & 0.49 & 0.21 & \\
\hline Female tibial size (mm) & $\begin{array}{l}0.36 \pm 0.02 a \\
\quad(n=9)\end{array}$ & $\begin{array}{l}0.33 \pm 0.03 b \\
\quad(n=9)\end{array}$ & $\begin{array}{l}0.36 \pm 0.02 a \\
\quad(n=35)\end{array}$ & $\begin{array}{l}0.36 \pm 0.02 a \\
\quad(n=46)\end{array}$ & \\
\hline Male tibial size $(\mathrm{mm})$ & $\begin{array}{l}0.33 \pm 0.02 a \\
\quad(n=3)\end{array}$ & $\begin{array}{l}0.32 \pm 0.02 b \\
\quad(n=4)\end{array}$ & $\begin{array}{l}0.33 \pm 0.03 b \\
\quad(n=36)\end{array}$ & $\begin{array}{l}0.34 \pm 0.02 b \\
\quad(n=12)\end{array}$ & \\
\hline Egg load & $\begin{array}{c}19.77 \pm 10.50 a \\
(n=9)\end{array}$ & $\begin{array}{l}8.48 \pm 6.75 a \\
\quad(n=9)\end{array}$ & $\begin{array}{l}11.44 \pm 7.45 a \\
\quad(n=35)\end{array}$ & $\begin{array}{c}11.30 \pm 10.70 a \\
(n=46)\end{array}$ & \\
\hline $\begin{array}{l}\text { Developmental time of females } \\
\text { (days) }\end{array}$ & $\begin{array}{c}30.33 \pm 2.65 a \\
(n=9)\end{array}$ & $\begin{array}{c}22.33 \pm 3.74 b \\
(n=9)\end{array}$ & $\begin{array}{c}22.66 \pm 2.83 b c \\
(n=35)\end{array}$ & $\begin{array}{c}21.89 \pm 2.08 c \\
(n=46)\end{array}$ & \\
\hline $\begin{array}{l}\text { Developmental time of males } \\
\text { (days) }\end{array}$ & $\begin{array}{c}31.33 \pm 1.53 a \\
(n=3)\end{array}$ & $\begin{array}{c}26.25 \pm 7.23 b \\
(n=4)\end{array}$ & $\begin{array}{c}22.86 \pm 2.83 b c \\
(n=36)\end{array}$ & $\begin{array}{c}20.50 \pm 1.93 c \\
(n=12)\end{array}$ & \\
\hline
\end{tabular}




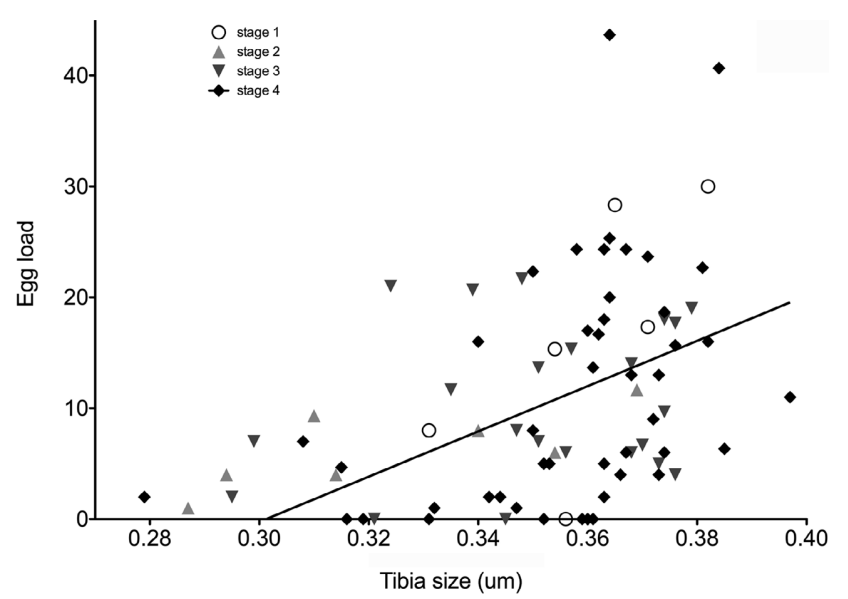

Fig. 2. Correlation between the egg load of females that emerged from each the host instars and tibial size. Only the significant correlation for the fourth instar is shown.

time of the sexes $(\mathrm{F}=0.14, \mathrm{DF} 1=1, \mathrm{DF} 2=152, \mathrm{P}=0.71)$ and no interaction between the two factors $(\mathrm{F}=1.52, \mathrm{DF} 1$ $=3, \mathrm{DF} 2=146, \mathrm{P}=0.21)$ (Table 2).

\section{DISCUSSION}

According to Armand et al. (1990, 1991) and Booth (1992), T. insidiosus mainly oviposit in the fourth and fifth instar of the pear psyllid C. pyri, whereas for C. pyricola, the studies of McMullen (1966), Guttierez (1966) and Booth (1992) suggest that this parasitoid oviposit in all instars. In our study, we also observed this parasitoid inserting its ovipositor in all host instars and that higher mummy productions were recorded when eggs were laid in third and fourth instars, as in the study of Gutierrez (1966). However, there was a low acceptance fifth instar hosts, in which no parasitoid developed.

Our results indicate that attraction and acceptance of fifth instar psyllids by $T$. insidiosus was low as there were few antennal contacts and ovipositor insertions and no mummies were produced. T. insidiosus stabs and searches with its ovipositor honeydew droplets looking for a potential host (Gutierrez, 1966; McMullen, 1966) and no eggs have been recovered from honeydew droplets (Gutierrez, 1966), suggesting that this parasitoid is able to probe and evaluate its environment using its ovipositor. This probably means that the ovipositor insertions into fifth instar psyllids only assessed host quality and did not result in an oviposition and hence the absence of mummies of this instar. Alternatively, fifth instars are probably too large and too advanced in their development to allow proper parasitism and development of T. insidiosus. Indeed, advanced instars of psyllids are able to escape the parasitoid more easily than earlier instars (Villagra et al., 2002). Such differences in escape behaviour between host instars are commonly reported in aphid-parasitoid interactions, in which more mature hosts are also generally more likely to encapsulate parasitoid eggs (Colinet et al., 2005). For example, it has also been shown that the immune response of the last instar of the aphid Toxoptera citricida to parasitism is greater than that of younger instars (Walker \& Hoy, 2003). The absence of mummies of fifth instar psyllids could therefore be explained by a combination of the behavioural and immune responses of the psyllid to parasitoid attack (Colinet et al., 2005). Fifth instars of $C$. pyri are therefore completely unsuitable for parasitoid development.

Parasitoids spent more time resting and less time exploring when presented with the first two instars and first instar hosts were the least suitable for T. insidiosus of the instars which were mummified. Few antennal contacts and ovipositor insertions were recorded for second and fifth instar hosts. First and second instars together accounted for only $20 \%$ of the total number of mummies produced. In general, the percentage parasitism of young host instars are associated with a higher mortality as they are more susceptible to oviposition injuries from stinging and/or venom (Colinet et al., 2005). In addition, the percentage mortality of young parasitized instars could be high because they are more likely to die between successive moults. All parameters taken together, indicate that third and fourth instar psyllids are the most suitable hosts for the development of T. insidiosus, both qualitatively and quantitatively.

We found that $T$. insidiosus was more motivated to forage for hosts in the presence of third, fourth and fifth psyllid instars, with more time spent moving and less time spent resting than when presented with first and second instars. Clues left by older psyllids (e.g. honeydew, exuviae and chemical volatiles) could stimulate the locomotor activity of the parasitoid and thus increase its probability of finding hosts. This is reported for the encytrid parasitoid Psyllaephagus pistaciae whose searching time, locomotion, antennal drumming and ovipositor probing behaviour increased in the presence of pistachio psylla honeydew (Mehrnejad \& Copland, 2006). The anthocorid Orius sauteri tends to forage more and to lay more eggs in the presence of the pear psylla Cacopsylla chinensis honeydew (Ge et al., 2019). Our results indicate that the amount and/or the quality of the clues present in the environment may be important cues for the parasitoid. Determining the nature of the clues influencing the exploratory behaviour of T. insidiosus could be an additional step in the unravelling of the factors determining the interactions between psyllids and parasitoids (Tougeron et al., 2021).

We found that third and fourth instar psyllids are the most suitable hosts for oviposition, as $80 \%$ of the mummies obtained in this study were of these two instars. Although they are larger and therefore more difficult for the parasitoid to handle than first and second instar hosts, they appear to be the most suitable candidates for the female parasitoid, given the trade-off between the nutritional quality of the host and its behavioural and immune defence capabilities (Colinet et al., 2005).

$T$. insidiosus spent nearly half of the time grooming regardless of the host instar encountered. Psyllids, especially the early instars, produce large amounts of honeydew (Civolani, 2012), which is a highly concentrated sugar solution (Le Goff et al., 2019). After an ovipositor insertion, residues of honeydew on the parasitoids cuticle probably promote bacterial and/or fungal infections. Selection likely 
favoured individuals that spent a lot of time cleaning themselves (legs, ovipositor, antennae), because this behaviour may not only help parasitoids to live longer, but also enables them to maintain high levels of locomotor activity and host detection (Zhukovskaya et al., 2013). For psyllids, a high honeydew production could also be a protection against parasitoids. Indeed, the honeydew of the pear psylla, $C$. chinensis, limits the foraging behaviour of its predators and might be a physical defence for this psyllid (Ge et al., 2019). Moreover, T. insidiosus attempts to oviposit in honeydew droplets might alert psyllid immatures to its presence and give them more time to escape. When attacking aphids, parasitoids also waste time manipulating and inserting their ovipositor into aphid exuviae (Muratori et al., 2008). Finally, the time $T$. insidiosus spends grooming is time not spent searching for a host. An analysis the behaviour of this parasitoid when exuviae of different instars and/or honeydew are present could clarify the role that psyllid waste might play in its defence.

Regarding the parasitoid fitness indicators, the offspring of parasitoids that developed in the first three host instars have a balanced sex ratio and those that developed in fourth instar psyllids were mostly females. It is known that host size/instar can influence the sex ratio of parasitoid offspring: with eggs laid in large hosts mainly developing into females (Van Den Assem et al., 1982; Jervis \& Kidd, 1986; Bernal et al., 1997). This strategy is consistent with the host size distribution model, which assumes that the amount of resource available for parasitoid development determines its fitness (Charnov, 1976; Charnov \& Skinner, 1985). Thus, it is more profitable for a female parasitoid to lay female eggs in large hosts that provide more resources (Jervis \& Kidd, 1986) as their offspring will have a higher egg load. Our experiments were conducted with solitary females, but it would be interesting to test whether this species produces more males when it has to compete for large hosts, as predicted by the theory of local mate competition (Hamilton, 1967).

The parasitoids that emerged from third and fourth instar psyllids were larger than those emerging from second instar psyllids, probably because they contain more reserves, which enable the parasitoid to achieve a larger size. More surprisingly, female parasitoids that developed in first instar hosts were as large as those that developed in third and fourth instar hosts. One mechanism that would explain these observations is that when an egg is laid in a first instar host, the egg does not begin to develop until the psyllid host reaches a more advanced instar as suggested by McMullen (1966).

This hypothesis is supported by the fact that individuals developed in first instar hosts took longer to develop than those that developed in other instars. It is also possible that parasitoid larvae develop less rapidly in such a host in order to keep it alive longer, thus ensuring the completion of their development. These hypotheses could be confirmed by dissecting second, third and fourth instars that were parasitized during the first instar and identifying the developmental instar of the parasitoid.
We recorded a fairly low egg load in T. insidiosus regardless of the host instar in which they developed, suggesting that this species is synovogenic and produces eggs throughout its life (approximately 20 days when fed under laboratory conditions (Berthe, 2018)). Furthermore, generally for parasitoids the larger the female the greater the egg load (Jia \& Liu, 2018). In our study, this relationship was only recorded for individuals emerging from fourth instar hosts, confirming that this instar is the most suitable for parasitoid development. Some large females, however, had no or few mature eggs. It is possible that the method used to evaluate egg-load is not suitable for this parasitoid and that some eggs may have been lost in the process. It is also possible that a stimulus such as psyllid honeydew, host feeding, or simply the presence of the host, is necessary to stimulate egg production (Aung et al., 2012; Pan et al., 2017).

Finally, although host feeding behaviour was not associated with host instar, it may play an important role in the ecology of $T$. insidiosus and its interaction with its host. This behaviour is described for other species of encyrtidae (Aung et al., 2012) but not T. insidiosus. According to our observations $T$. insidiosus host feeds either when it accidentally kills the host during oviposition (S2) or when it deliberately kills the host, probably in order to get protein in order to increase its egg-load. In our experiments, the number of host-feeding events recorded was very low, likely because the females were fed, hydrated and already had a full egg load. Therefore, their only optimal foraging strategy under these conditions was probably to lay as many eggs as possible. To better understand the conditions resulting in host-feeding, further experiments are needed on fertilized females with poor access to food, and/or with low egg loads. Such an experiment would highlight the trade-off between feeding to replenish their reserves/egg load and laying eggs, when a female encounters a psyllid immature. It is also possible that $T$. insidiosus is able to discriminate between a parasitized and a non-parasitized host, as is the case for most parasitoids (van Alphen \& Visser, 1990). Thus, a female arriving in a patch already visited by a conspecific would face a trade-off between super-parasitizing the host (Guttierrez, 1966) or feeding on a parasitized host and thus decreasing the competition pressure encountered by its offspring. This decision-making will probably be influenced by female egg-load, but this hypothesis needs to be tested.

To conclude, the purpose of this study was to determine key elements in the interaction between the pear psyllid C. pyri and its specific parasitoid, T. insidiosus, including the most suitable host instars for its development. We show that fourth instars are the most suitable host, both behaviourally and physiologically, for the parasitoid to produce a high quantity and high-quality offspring. From a biological control perspective, the best time to release parasitoids to have the highest probability of controlling a psyllid population would be early in the season when psyllids of the first generation have reached the fourth instar. Indeed, by parasitizing the fourth instar of C. pyri, T. insid- 
iosus will mainly parasitize psyllids that have escaped all other mortality factors and are at the end of their developmental cycle and about to reproduce. Thus, this parasitoid could potentially be used to reduce the abundance of the first and second generations of this psyllid pest (Armand et al., 1991; Tougeron et al., 2021), however the effect of the parasitoid on the diseases that pear psyllid immatures can infest/infect pear trees with during their development (sooty mould fungus and phytoplasma) is still unknown and remains to be evaluated.

ACKNOWLEDGEMENTS. This research was supported by grant $12 / 1 / 7798$ of the PPP call of the Walloon Region, by an additional grant from Viridaxis S.A. and by the Interreg-Proverbio project funded by SPW-Feder-Interreg (https://www.interreg-fwvl.eu). KT and FR were supported by the F.R.S.-FNRS. This publication is number BRC361 of the Biodiversity Research Centre.

AUTHOR CONTRIBUtION. GJLG, JB, TH designed the study, JB did the experiments, GJLG and JB analysed the data. BD, OL, GJLG caught the insect to start the rearing, maintained the rearing and the plant cultures. GJLG, KT, FR and TH wrote the manuscript. All authors contributed to manuscript improvement and gave their final approval for publication.

CONFLICT OF INTEREST STATEMENT. The authors of this article do not present any conflict of interest.

DATA AVAILABILITY STATEMENT. The datasets analyzed for the current study are available at the following DOI: https://doi. org/10.6084/m9.figshare.13187642.v1.

\section{REFERENCES}

AlbitTar L., Ismail M., Bragard C. \& Hance T. 2016: Host plants and aphid hosts influence the selection behaviour of three aphid parasitoids (Hymenoptera: Braconidae: Aphidiinae). - Eur. J. Entomol. 113: 516-522.

Armand E., Lyoussoufi A., D’Arcier F.F. \& Rieux R. 1990: Interrelations entre les populations du psylle du poirier Psylla pyri (L.) (Hom., Psyllidae) et le complexe de ses parasitoïdes dans un verger traité du sud-est de la France. - J. Appl. Entomol. 110: 242-252.

Armand E., Lyoussouf A. \& Rieux R. 1991: Evolution du complexe parasitaire des psylles du poirier Psylla pyri et Psylla pyrisuga (Homoptera: Psyllidae). — Entomophaga 36: 287-294.

Augustin J., Boivin G., Brodeur J. \& Bourgeois G. 2020: Effect of temperature on the walking behaviour of an egg parasitoid: disentangling kinetic response from integrated response. Ecol. Entomol. 45: 741-750.

Aung K.S.D., TaKasu K., Ueno T. \& TaKagi M. 2012: Effect of host-feeding on reproduction in Ooencyrtus nezarae (Ishii) (Hymenoptera: Encyrtidae), an egg parasitoid of the bean bug Riptortus clavatus. - J. Fac. Agric. Kyushu Univ. 57: 115-120.

Avilla J., Artigues M., Marti S. \& Sarasua M.J. 1992: Parasitoides de Cacopsylla pyri (L.) (= Psylla pyri (L.)) presentes en una plantación comercial de peral en Lleida no sometida a tratamientos insecticidas. - Bol. San. Veg. Plagas 18: 133138.

Bartlett B.R., Clausen C.P., DeBach P., Goeden R.D., Legner E.F., McMurtry J.A., Oatman E.R., Bay E.C. \& Rosen D. 1978: Introduced Parasites and Predators of Arthropod Pests and Weeds: A World Review. Agriculture Handbook No. 480, UDSA, Washington D.C., 551 pp.
Bernal J.S., WagGoner M. \& Gonzalez D. 1997: Reproduction of Aphelinus albidopus (Hymenoptera: Aphelinidae) on russian wheat aphid (Hemiptera: Aphididae) hosts. - Eur. J. Entomol. 94: 83-96.

BERTHE J. 2018: Evaluation de la capacité de parasitisme de Trechnites insidiosus pour le contrôle biologique du psylle du poirier Cacopsylla pyri. MSc Thesis, Université catholique de Louvain, Louvain la Neuve, $89 \mathrm{pp}$.

Воотн S.R. 1992: The Potential of Endemic Natural Enemies to Suppress Pear Psylla, Cacopsylla pyricola Förster, in the Hood River Valley, Oregon. PhD Thesis, Oregon State University, Corvallis, OR, $155 \mathrm{pp}$.

Buès R., Boudinhon L. \& Toubon J.-F. 2003: Resistance of pear psylla (Cacopsylla pyri L.; Hom., Psyllidae) to deltamethrin and synergism with piperonyl butoxide. - J. Appl. Entomol. 127: 305-312.

Bufaur M., Harizanova V. \& Stoeva A. 2010: Parasitoids of the pear sucker Cacopsylla pyri L. (Psyllidae) in Bulgaria - Morphology and biology. In: Traditions and Challenges of Agricultural Education, Science and Business. Scientific Works of the Agricultural University of Plovdiv, Vol. 55, Book 2, pp. 71-76.

BURTS E.C. 1983: Effectiveness of a soft-pesticide program on pear pests. - J. Econ. Entomol. 76: 936-941.

Chang J. 1977: Studies on the Susceptibility of Pear Trees to Pear Psylla, Psylla pyricola Foerster (Homoptera: Psyllidae). MSc Thesis, University of Ottawa, Ottawa, $140 \mathrm{pp}$.

ChARnov E.L. 1976: Optimal foraging, the marginal value theorem. - Theor. Popul. Biol. 9: 129-136.

Charnov E.L. \& SkINNER S.W. 1985: Complementary approaches to the understanding of parasitoid oviposition decisions. - Environ. Entomol. 14: 383-391.

Civolani S. 2012: The past and present of pear protection against the pear psylla, Cacopsylla pyri L. In Perveen F. (ed.): Insecticides - Pest Engineering. InTech, London, Rijeka, pp. 385408.

Civolani S., Peretto R., Caroli L., Pasqualini E., Chicca M. \& LeIS M. 2007: Preliminary resistance screening on abamectin in pear psylla (Hemiptera: Psyllidae) in Northern Italy. $-J$ Econ. Entomol. 100: 1637-1641.

Colinet H., Salin C., Boivin G. \& Hance T. 2005: Host age and fitness-related traits in a koinobiont aphid parasitoid. - Ecol. Entomol. 30: 473-479.

Emami M.S., Shishehbor P. \& Karimzadeh J. 2014: The influences of plant resistance on predation rate of Anthocoris nemoralis (Fabricius) on Cacopsylla pyricola (Förster). - Arch. Phytopathol. Plant Prot. 47: 2043-2050.

ERLER F. 2004: Natural enemies of the pear psylla Cacopsylla pyri in treatedvs untreated pear orchards in Antalya, Turkey. Phytoparasitica 32: 295-304.

FAOSTAT 2021: Global Fruit Production in 2019, by Selected Variety. URL: https://www.statista.com/statistics/264001/ worldwide-production-of-fruit-by-variety

GaJSKi D. \& PeKÁR S. 2021: Assessment of the biocontrol potential of natural enemies against psyllid populations in a pear tree orchard during spring. - Pest Manag. Sci. 77: 2358-2366. Ge Y., Liu P., Zhang L., Snyder W.E., Smith O.M. \& Shi W. 2020 : A sticky situation: honeydew of the pear psylla disrupts feeding by its predator Orius sauteri. - Pest Manag. Sci. 76: 75-84.

GoDFRAY H.C.J. 1994: Parasitoids: Behavioral and Evolutionary Ecology. Princeton University Press, 483 pp.

Guerrieri E. \& Noyes J.S. 2009: A review of the European species of the genus Trechnites Thomson (Hymenoptera: Chalcidoidea: Encyrtidae), parasitoids of plant lice (Hemiptera: Psylloidea) with description of a new species. - Syst. Entomol. 34: $252-259$. 
GutTIERrEz A.P. 1966: The Bionomics of Two Encyrtid Parasites of Psylla pyricola Forster in Northern California. MSc Thesis, University of California, Berkeley, $76 \mathrm{pp}$.

HamiLton W.D. 1967: Extraordinary sex ratios. A sex-ratio theory for sex linkage and inbreeding has new implications in cytogenetics and entomology. - Science 156: 477-488.

Heimpel G.E. \& Collier T.R. 1996: The evolution of host-feeding behaviour in insect parasitoids. - Biol. Rev. 71: 373-400.

HERARD F. 1985: Analysis of parasite and predator populations observed in pear orchards infested by Psylla pyri (L.) (Hom.: Psyllidae) in France. - Agronomie 5: 773-778.

HoRTON D.R. 1999: Monitoring of pear psylla for pest management decisions and research. - Integr. Pest Manag. Rev. 4: $1-20$.

JAWORSKa K., OlsZAK R.W. \& ZaJAC R.Z. 1996: Parasitization rate on the larvae of pear (Cacopsylla pyri) in orchards with differing intensity of chemical control. - Acta Horticult. 422: 334-335.

Jerinic-Prodanovic D., Protic L. \& Mihajlovic L. 2010: Predators and parasitoids of Cacopsylla pyri (L.) (Hemiptera: Psyllidae) in Serbia. - Pesticidi Fitomed. 25: 29-42.

JERvis M.A. \& KIDD N.A.C. 1986: Host-feeding strategies in Hymenopteran parasitoids. - Biol. Rev. 61: 395-434.

JIA Y.-J. \& LIU T.-X. 2018: Dynamic host-feeding and oviposition behavior of an aphid parasitoid Aphelinus asychis. - BioControl 63: 533-542.

Lacey L., Arthurs S., Horton D. \& Miliczky G. 2005: Spinosad and Granulovirus Effects on Codling Moth. Final Projekt Report. USDA-ARS, Yakima Agricultural Research Laboratory, Wapato, WA, 9 pp.

LamichHane J.R., Messéan A. \& Ricci P. 2019: Research and innovation priorities as defined by the Ecophyto plan to address current crop protection transformation challenges in France. Adv. Agron. 154: 81-152.

Le Goff G.J., Lebbe O., Lohaus G., Richels A., JacQuet N., BytTEBIER V. \& HANCE T. 2019: What are the nutritional needs of the pear psylla Cacopsylla pyri? - Arthr-Plant Interact. 13 : 431-439.

Mackauer M., Michaud J.P. \& VöLKL W. 1996: Host choice by Aphidiid parasitoids (Hymenoptera: Aphidiidae): Host recognition, host quality, and host value. - Can. Entomol. 128: 959-980.

Mansfield S. \& Mills N.J. 2002: Host egg characteristics, physiological host range, and parasitism following inundative releases of Trichogramma platneri (Hymenoptera: Trichogrammatidae) in walnut orchards. - Environ. Entomol. 31: 723-731.

McMullen R.D. 1966: New Records of chalcidoid parasites and hyperparasites of Psylla pyricola Förster in British Columbia. - Can. Entomol. 98: 236-239.

Mehrnejad M.R. \& Copland M.J.W. 2006: Behavioral responses of the parasitoid Psyllaephagus pistaciae (Hymenoptera: Encyrtidae) to host plant volatiles and honeydew. - Entomol. Sci. 9: 31-37.

MiliczKy E.R. \& HorTon D.R. 2005: Densities of beneficial arthropods within pear and apple orchards affected by distance from adjacent native habitat and association of natural enemies with extra-orchard host plants. - Biol. Contr. 33: 249-259.

Muratori F.B., Damiens D., Hance T. \& Boivin G. 2008: Bad housekeeping: why do aphids leave their exuviae inside the colony? - BMC Evol. Biol. 8: 338, 7 pp.

Oudeh B., Kassis W. \& Abu-Tara R. 2013: Seasonal activity of the predator, Anthocoris nemoralis (F.) and the parasitoid, Trechnites psyllae (R.) against the pear psylla Cacopsylla pyricola (F.) (Hemiptera: Psyllidae). - Egypt. J. Biol. Contr. 23: $17-23$.
Pan M.-Z., Wang L., Zhang C.-Y., Zhang L.-X. \& LiU T.-X. 2017: The influence of feeding and host deprivation on egg load and reproduction of an aphid parasitoid, Aphidius gifuensis (Hymenoptera: Braconidae). - Appl. Entomol. Zool. 52: 255-263.

Retan A. \& Peterson V. 1982: Pear psylla. — Insect Answers 1982: EB0906, 2 pp.

Sanchez J.A., López-Gallego E. \& La-Spina M. 2020: The impact of ant mutualistic and antagonistic interactions on the population dynamics of sap-sucking hemipterans in pear orchards. - Pest Manag. Sci. 76: 1422-1434.

SAnChez J.A. \& Ortin-Angulo M.C. 2012: Abundance and population dynamics of Cacopsylla pyri (Hemiptera: Psyllidae) and its potential natural enemies in pear orchards in southern Spain. - Crop Prot. 32: 24-29.

Seemüller E. \& Schneider B. 2004: 'Candidatus Phytoplasma mali', 'Candidatus Phytoplasma pyri' and 'Candidatus Phytoplasma prunorum', the causal agents of apple proliferation, pear decline and European stone fruit yellows, respectively. Inte. J. Syst. Evol. Microbiol. 54: 1217-1226.

Sigsgaard L., Esbjerg P. \& Philipsen H. 2006a: Controlling pear psyllids by mass releasing Anthocoris nemoralis and A. nemorum (Heteroptera: Anthocoridae). - J. Fruit Ornam. Plant Res. 14 (Suppl. 3): 89-98.

Sigsgaard L., Esbjerg P. \& Philipsen H. 2006b: Experimental releases of Anthocoris nemoralis F. and Anthocoris nemorum (L.) (Heteroptera: Anthocoridae) against the pear psyllid $\mathrm{Ca}$ copsylla pyri L. (Homoptera: Psyllidae) in pear. - Biol. Contr. 39: 87-95.

Tianna DuPont S. \& Strohm C.J. 2020: Integrated pest management programmes increase natural enemies of pear psylla in Central Washington pear orchards. - J. Appl. Entomol. 144: 109-122.

Tianna DuPont S., Strohm C., Nottingham L. \& Rendon D. 2021: Evaluation of an integrated pest management program for central Washington pear orchards. - Biol. Contr. 152: 104390, 13 pp.

Tougeron K., Iltis C., Renoz F., Albittar L., Hance T., Demeter S. \& LE GofF G.J. 2021: Ecology and biology of the parasitoid Trechnites insidiosus and its potential for biological control of pear psyllids. - Pest Manag Sci ps.6517 (in press).

Unruh T.R., Westigard P.H. \& Hagen K.S. 1994: Pear psylla. In Nechols J.R. (ed.): Biological Control in the Western United States. DNR Publ. 3361, University of California, Oakland, pp. 95-100.

VAN AlPhen J.J.M. \& VisSER M.E. 1990: Superparasitism as an adaptive strategy for insect parasitoids. - Annu. Rev. Entomol. 35: 59-79.

Van Den Assem J., GiJswijt M.J. \& NüBel B.K. 1982: Characteristics of courtship and mating behaviour used as classificatory criteria in Eulophidae: Tetrastichinae (Hymenoptera), with special reference to the genus Tetrastichus. - Tijdscr. Entomol. 125: 205-219.

Villagra C.A., Ramirez C.C. \& Niemeyer H.M. 2002: Antipredator responses of aphids to parasitoids change as a function of aphid physiological state. - Anim. Behav. 64: 677-683.

WAlker A.M. \& Hoy M.A. 2003: Responses of Lipolexis oregmae (Hymenoptera: Aphidiidae) to different instars of Toxoptera citricida (Homoptera: Aphididae). - J. Econ. Entomol. 96: $1685-1692$.

Zhukovskaya M., Yanagawa A. \& Forschler B.T. 2013: Grooming behavior as a mechanism of insect disease defense. - Insects 4: 609-630. 
Received May 19, 2021; revised and accepted August 20, 2021

Published online September 23, 2021

Online supplementary files:

S1 (http://www.eje.cz/2021/028/S01.pdf).

S2 (http://www.eje.cz/2021/028/S02.m4v). 